\title{
Weight Gain in Malnourished Children after 5 Months Food Supplementation in a Slum Setting in Bangladesh
}

\author{
Mustafa Mahfuz*, Tahmeed Ahmed, A. M. Shamsir Ahmed, M. Munirul Islam, M. I. Hossain \\ Centre for Nutrition and Food Security, International Centre for Diarrhoeal Disease Research, Bangladesh \\ (icddr, b), Dhaka, Bangladesh \\ Email: ${ }^{*}$ mustafa@icddrb.org
}

Received 26 May 2014; revised 2 July 2014; accepted 14 July 2014

Copyright (C) 2014 by authors and Scientific Research Publishing Inc.

This work is licensed under the Creative Commons Attribution International License (CC BY).

http://creativecommons.org/licenses/by/4.0/

(c) () Open Access

\begin{abstract}
We examined the rate of weight gain and absolute weight gain of underweight children (weightfor-age Z score < -2) aged between 6 - 24 months living in a slum of Dhaka city, in response to two different regimens of supplementary feeding. Comparison was also made with the weight gain of a healthy group of children from the same locality. In total 161 children, including 68 healthy children representing the control group, were enrolled for the 5 months supplementation. The two regimens of feeding were either ready-to-use therapeutic food (RUTF, Plumpy'Nut) or locally made cereal-based supplementary food Pushti packet which was recommended in the National Nutritional Program. No food supplementation was provided to control children. All children received vitamin $A$ as part of the six-monthly national program, albendazole for deworming, immunization, and health and nutrition education. Multiple micronutrient powder (MNP) was provided only to Pushti packet and control children. The rate of weight gain on RUTF was $1.69 \mathrm{~g} / \mathrm{kg} /$ day during the first month and gradually declined to $0.9 \mathrm{~g} / \mathrm{kg} / \mathrm{day}$ at the final month of the trial, whereas, the rate of weight gain on Pushti packet was $0.77 \mathrm{~g} / \mathrm{kg} /$ day during the first month declining to 0.70 $\mathrm{g} / \mathrm{kg} / \mathrm{day}$ at the end of the trial. Rate of weight gain in the control group was steady between 0.47 $0.50 \mathrm{~g} / \mathrm{kg} /$ day. Absolute weight gains of $1085 \mathrm{~g}, 790 \mathrm{~g}$ and $730 \mathrm{~g}$ were observed in the RUTF, Pushti packet and the control groups, respectively which were significantly higher in the RUTF group. There was no statistically significant difference between the RUTF and Pushti packet groups in terms of rate of weight gain. Overall, weight gain was unsatisfactory for both supplementation groups. Better absolute weight gain was observed with RUTF supplementation compared to Pushti packet which prevented further deterioration in weight among the malnourished children.
\end{abstract}

\footnotetext{
"Corresponding author.
}

How to cite this paper: Mahfuz, M., Ahmed, T., Shamsir Ahmed, A.M., Munirul Islam, M. and Hossainm M.I. (2014) Weight Gain in Malnourished Children after 5 Months Food Supplementation in a Slum Setting in Bangladesh. Food and Nutrition Sciences, 5, 1370-1378. http://dx.doi.org/10.4236/fns.2014.514149 


\section{Keywords}

\section{Malnutrition, RUTF, Supplementation, Underweight, Bangladesh}

\section{Introduction}

Globally undernutrition is associated with more than one-third of all child deaths [1] and about one-third of children in the developing countries are undernourished [2]. Underweight is the combined effect of both acute malnutrition (wasting) and chronic malnutrition (stunting) [3] [4]. The Lancet series on Maternal and Child Nutrition 2013 has shown that 100 million (16\%) children under 5-year-old worldwide are still underweight and around 52 million (8\%) are wasted [5]. Rate of malnutrition in Bangladesh is around twice more than that in Sub-Saharan Africa [6]. Therefore, with 36\% of children under 5-year-old underweight, $41 \%$ children stunted and $16 \%$ wasted, Bangladesh belongs to the countries with very high burden of childhood malnutrition [7]. Inappropriate food intake, inadequate absorption, emotional factors such as parental deprivation, increased infections and excessive nutrient loss occurring in persistent diarrhea are some of the leading causes of malnutrition [8]. A food-based approach is certainly the best way to prevent and treat malnutrition of subtle degrees of severity [9] [10]. These appropriate dietary products should be preferred on the basis of nutritional needs of the community, contextual factors, the availability of the products, and likelihood of impact [10]. However, due to the cost of the recommended energy and nutrient-dense foods for malnourished children, low-income families might find them unaffordable [10]. It is imperative to provide malnourished children, particularly to those living in food insecure conditions with supplementary food, either prepared at home or as ready to eat foods. Traditionally, fortified blended flours have been the prime choice as the supplementary food for malnourished children, however, a newly developed peanut-based ready-to-use supplementary food (RUSF) has been recommended for the treatment of moderate acute malnutrition [11] [12] and another peanut-based but more energy-dense ready-to-use therapeutic food (RUTF) for the treatment of severe acute malnutrition [13]. However, there are scarcities of data on the impact of locally developed commodities with that of standard ready-to-use food developed for treating acute malnutrition [10].

"Etiology, Risk Factors and Interactions of Enteric Infections and Malnutrition and the Consequences for Child Health and Development” (MAL-ED) is a multi-site research aimed at gaining a better understanding of the risk factors for malnutrition, enteric diseases and associated health consequences in children of developing countries [14]. The project is now conducting epidemiological studies (longitudinal and case-control) in eight developing countries including Bangladesh. The hypothesis of the MAL-ED mainly focuses on malnutrition and its interaction with enteric infections and gut physiological changes. In Bangladesh, the study is conducted among residents of an under-privileged urban community in Mirpur, Dhaka.

This paper is based on an operational research on interventions for moderate and severe acute malnutrition. All the children aged 6 - 24 months in the study area were screened for weight-for-age z-score. The malnourished children were severe to moderately underweight children (weight-for-age $\mathrm{z}$ score, WAZ $<-2$ based on the new WHO growth reference) aged between 6 to 24 months, whereas, the controls were well-nourished children (WAZ > -1) who were matched with the malnourished children for sex, and area of residence. All malnourished children were provided with standard of care nutritional supplementation as recommended by the erstwhile national nutrition program (NNP) of Bangladesh that consisted of a supplementary food made from locally available ingredients called Pushti packet (PP: see below for composition), and behavior change communication (BCC), high potency vitamin A capsules at six-monthly intervals, deworming at enrollment and immunization against the illnesses covered by the expanded program on immunization. Children in the control group received all the above interventions but no food supplementation. Both groups received multiple micronutrient powder (MNP: contains 1 RDA of vitamin A, iron, folic acid, zinc and vitamin C) for fortification of the lunch meal. However, initial observation revealed that the malnourished children were not gaining enough weight despite supervised feeding of PP. To explore the issue we did an interim analysis to look at the impact of supplementary feeding among malnourished children $(n=125)$. After 5 months of PP supplementation the mean weight gain was $810 \pm 445 \mathrm{~g}$ with a median of $770 \mathrm{~g}$. If we follow the growth standard chart, the normal weight gain in this age group is $1000 \mathrm{~g}$ over 5 months period. For the control children with no food supplementation (n 
= 138), the weight gain was $732 \pm 611 \mathrm{~g}$, median $750 \mathrm{~g}$. The normal weight gain in this age group is also $1000 \mathrm{~g}$ over 5 months period of time.

We conducted an operations research to investigate the weight gain of a subsample of malnourished children from the MAL-ED study. The operations research followed the MAL-ED protocol, however, the malnourished children were divided initially into three feeding regimens: one group received Pushti packet (PP), one group received ready-to-use therapeutic food (Plumpy'Nut) and the third group received enhanced PP (EPP) where 7 $\mathrm{ml}$ of vegetable oil was added to PP to make it more energy-dense. All regimens were provided with the NNP recommending other standard of care interventions as mentioned above. The objective of the operations research was to evaluate the effectiveness of the PP in comparison to the RUTF and EPP in terms of weight gained by the children during 5 months period.

\section{Methodology}

The study compared the rate of weight gain and absolute weight gain of malnourished children after receiving either PP, EPP or RUTF 6 days a week for 5 months with healthy children who served as the control group.

\subsection{Study Area}

The study was carried out in the community nutrition centers established by MAL-ED study located in the Bauniabadh area of Mirpur, Dhaka.

\subsection{Participant Enrollment}

We enrolled 25 moderate to severely malnourished children (WAZ $<-2$ SD) aged 6 - 24 months. For the EPP group it was only possible to enroll 9 children because this arm was stopped due to dislike of the food by the children. For each child in the RUTF and EPP groups, double the number of malnourished children with PP supplementation and healthy controls were taken for the analysis. Finally, we randomly enrolled 68 children in the PP supplementation group and 68 children as controls. All the children in the different supplementary feeding groups and the healthy controls were matched by age and area of residence. The study enrollment profile is illustrated in Figure 1.

\subsection{Operation Definition}

Absolute weight gain was defined as the absolute weight increment compared to the baseline during the 5 month

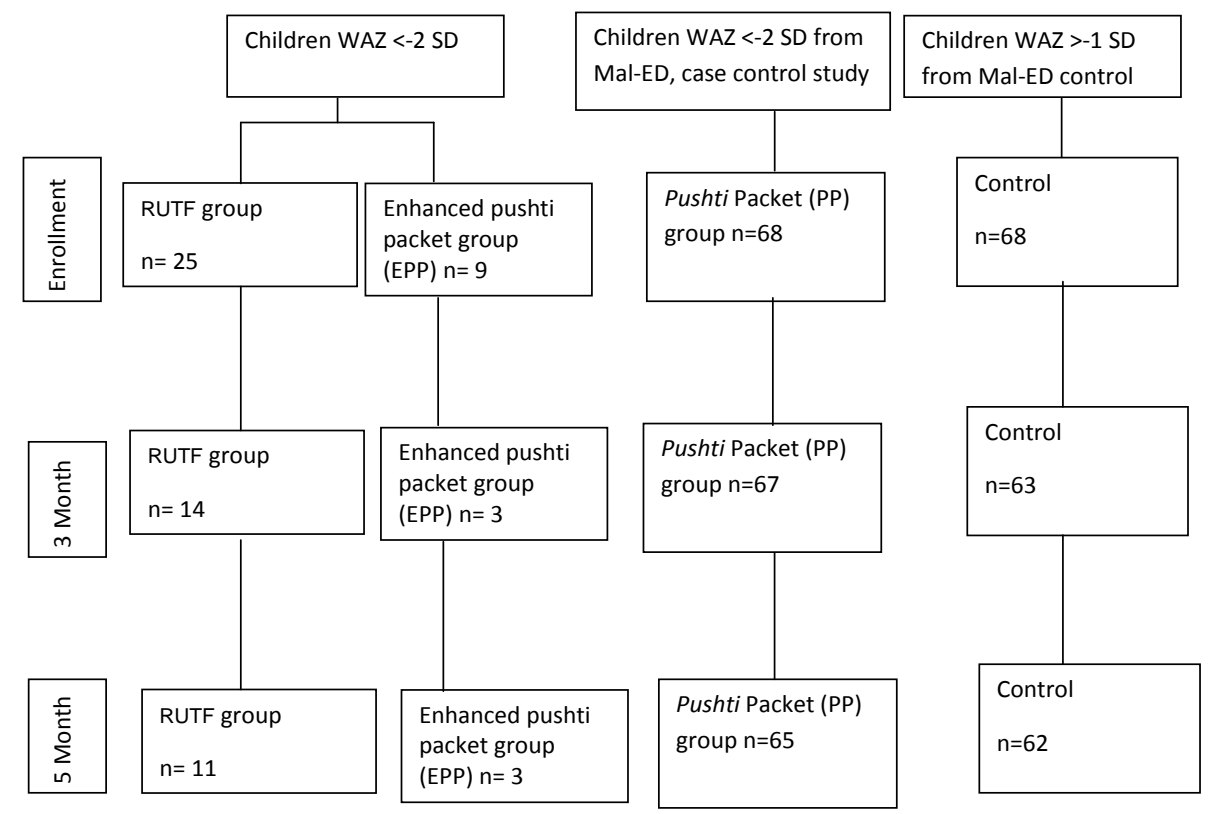

Figure 1. Study profile. 
period and rate of weight gain was expressed as $\mathrm{g} / \mathrm{kg} /$ day increment in body weight of the participating children.

\subsection{The Food Supplement Interventions}

\subsubsection{RUTF}

Ready-to-use therapeutic food (RUTF) was developed for the home treatment of severe acute malnutrition, and its nutritional value is equivalent to F-100 milk. The ingredients used in RUTF are peanut paste, vegetable fat, sugar, skimmed milk powder, vitamins and minerals. It is available in 92 gm sachet, each sachet providing 500 kcal of energy [15]. For this study, children with WAZ $<-3$ in the RUTF group received 1 sachet of RUTF daily and children with WAZ -2 to -3 SD received 13.6 gm less amount of RUTF to make it appropriate for moderate malnutrition.

\subsubsection{Pushti packet}

Each Pushti packet (PP) contained 20 gm of roasted rice powder, 10 gm of roasted lentil powder, 5 gm of molasses and $3 \mathrm{gm}$ of soy bean oil. Each PP provides $150 \mathrm{kcal}$ of energy, $11 \%$ of which comes from its protein content. In order to ensure adequate nutrition, children with severe malnutrition (WAZ $<-3$ ) in this group were provided with 3 packets daily (450 kcal), while moderately malnourished children received 2 packets of PP daily (300 kcals) for 5 months or until graduation by achieving WAZ score of more than or equal to -2 (or WAZ $\geq-1$ for children with moderate malnutrition).

All the participants were also provided with high potency vitamin A, once in every 6 months $(100,000$ international units for children 6 - 12 months old and 200,000 units for older children), and $200 \mathrm{mg}$ of anti-helminthic albendazole at enrollment if the child is more than 1 year old. MNP was provided only to PP, EPP and control children.

Diarrheal episodes of the children during the supplementation period, if any, were treated with ORS and oral zinc treatment as per WHO/UNICEF recommendations. The primary caregivers were encouraged to have their children vaccinated at the nearest EPI center for poliomyelitis, TB, diphtheria, pertussis, tetanus, and measles. Additionally, the children also received typhoid, hepatitis B and Hemophilus influenzae vaccines from the research project. Children with severe acute malnutrition (SAM: weight-for-length $<-3$, and/or bipedal edema) were admitted to the icddr, $b$ hospital for management of SAM.

\subsection{Data Collection}

PP, EPP and RUTF were given to the children when they came daily to one of the four community nutrition centers established for the study. The primary caregivers of the participants were given the allocated daily dosage of supplementary food and direct observation of the feeding was ensured.

\subsection{Anthropometric Measurement}

All anthropometric measurements were done according to the Mal-ED standard operating procedure. The World Health Organization's child growth standard was followed by using WHO Anthro 2005 software. This study recruited only those children whose caregivers signed the informed consent form after being informed about the purpose of the study. The study was approved by the institutional review board of icddr, b.

\subsection{Statistical Procedure}

All statistical analyses were carried out using SPSS v17.0. Descriptive statistics were performed to define the baseline characteristics and anthropometric indicators of the participants, whereas, one-way ANOVA were carried out to identify any significant difference between the mean of the variables used for the groups. In order to explore the primary outcome, mixed design repeated measure ANOVA with the feeding regimen as independent measures and repeated measure on the rate of weight gain with Tukey's test was carried out to examine whether there is any significant differences between the regimen groups in terms of rate of weight gain and absolute weight gain.

\section{Results}

At enrollment there were 25 children in the RUTF group, 9 children in the Enhanced Pushti packet (EPP) group, 
68 in the Pushti packet (PP) group and 68 in the control group. In the EPP group it was possible to enroll only 9 children because the taste of EPP was not accepted by the children and few reported vomiting. We eventually discontinued further recruitment, and only 3 children were followed up for the whole intervention period. Therefore, we did not include the growth data of these 3 children on EPP in the final analysis.

The RUTF group had 52\% females, while PP and the control groups both had 58.8\% females. There was no statistically significant difference between the groups' mean age $(p=0.99)$ or maternal age $(p=0.14)$. However, the baseline weight, weight-for-age z-score (WAZ) and MUAC were significantly different when the control group is compared to RUTF and PP groups ( $=0.000$, Table 1$)$; there was no statistically significant difference between the RUTF and control groups in terms of baseline weight and WAZ $(>0.05)$. The mean years of maternal schooling were 2.52, 3.46 and 5.29 years in the RUTF, PP and the control groups respectively and was significantly different among the groups $(\mathrm{p}<0.01)$. Tukey's post-hoc analysis indicates no statistically significant difference in terms of mothers' schooling years between the RUTF and PP groups, but both groups were significantly different from the control group. Levene's test confirms that the assumption of homogeneity of variance was not violated for any variables. There is no statistical difference between the groups in terms of the selected baseline nutritional indicators such as early initiation of breast feeding, colostrum feeding, exclusive breast feeding, introduction of soft and semisolid food, and utilization of Iodized salt for cooking (Table 2).

In terms of rate of weight gain, the RUTF group had a mean increment of $1.69 \mathrm{~g} / \mathrm{kg} / \mathrm{day}$ during the first month, which gradually declined to $1.21 \mathrm{~g} / \mathrm{kg} /$ day during the 4 month, and then to $0.9 \mathrm{~g} / \mathrm{kg} / \mathrm{day}$ at the end of $5 \mathrm{month}$ period. Children in the PP group initially demonstrated an average of $0.77 \mathrm{~g} / \mathrm{kg} /$ day increment during the first month, which increased to $0.90 \mathrm{~g} / \mathrm{kg} / \mathrm{day}$ at the end of the second month, before decreasing to $0.78 \mathrm{~g} / \mathrm{kg} / \mathrm{day}$ during the third month interval and steadily decreasing further to $0.70 \mathrm{~g} / \mathrm{kg} / \mathrm{day}$ at the end of the trial. Children in the control group maintained a steady weight gain of $0.49 \mathrm{~g} / \mathrm{kg} /$ day during the whole trial period (Table 3 , Figure 2, Figure 3).

As confirmed by one-way ANOVA and post-hoc Tukey's test, there was no statistically significant difference in terms of rate of weight between the RUTF and the PP groups at any interval ( $p>0.05$ ). However, statistically significant difference rate of weight gain was observed between RUTF and the control groups at all the intervals, and between the PP and control groups from the second month till the end of the trial ( $p>0.05$ at $1^{\text {st }}$ month interval).

The two-way repeated measure ANOVA did not detect any overall statistically significant difference between the regimens in terms of rate of weight gain during the trial duration, but there is statistically significant difference between both the intervention (Plumpy'Nut and PP regimen) and the control regimen in terms of rate of weight gain.

Moreover, in terms of overall absolute weight gain achieved during the trial period, significant difference was observed between the three groups. RUTF accounted for an increase in absolute weight gain of $1085 \mathrm{~g}$, whereas, the PP and the control groups achieved $790 \mathrm{~g}$ and $730 \mathrm{~g}$ respectively after 5 months of intervention. The difference in absolute weight gain between the RUTF and both PP and control groups is statistically significant. However, the $60 \mathrm{~g}$ difference in terms of absolute weight gain between the PP and control groups was not statistically significant (Table 3 ).

In addition, difference in the absolute weight gain at $1^{\text {st }}$ and $5^{\text {th }}$ month attained by the three groups was not statistically significant. However, absolute weight gain attained by RUTF group was significantly different from the other two groups during the $2^{\text {nd }}, 3^{\text {rd }}$ and $4^{\text {th }}$ months, but the difference between the PP and control groups was

Table 1. Baseline anthropometric and socio-economic indicators of the three supplementation groups.

\begin{tabular}{ccccc}
\hline & \multicolumn{2}{c}{ Intervention n = 93 } & Control n = 68 \\
\cline { 1 - 4 } & Subhead & RUTF n = 25 & Pushti packet $\mathbf{n}=68$ & \\
\hline Participant's age & Months (mean, 95\% CI) & $15.2(13.27-17.2)$ & $15.21(14.05-16.4)$ & $15.2(14.03-16.4)$ \\
Mother's age & Years (mean, 95\% CI) & $23.24(21.71-24.77)$ & $25.6(24.26-27.04)$ & $24.9(23.67-26.17)$ \\
Mother's education & Years (mean, 95\% CI) & $2.52(1.38-3.66)$ & $3.46(2.70-4.21)$ & $5.29(4.39-6.20)^{*}$ \\
Baseline weight & Kg (mean, 95\% CI) & $7.31(6.93-7.69)$ & $7.28(7.04-7.53)$ & $9.43(9.16-9.70)^{*}$ \\
Weight-for-age z-score & Unit & $-2.68[(-2.93)-(-2.43)]$ & $-2.66[(-2.82)-(2.51)]$ & $-0.4[(-0.50)-(0.31)]^{*}$ \\
MUAC & $\mathrm{cm}$ & $12.73(12.44-13.0)$ & $13.11(12.91-13.03)$ & $14.87(14.67-13.99)^{*}$ \\
\hline
\end{tabular}

${ }^{*} \mathrm{p}<0.001$. 
Table 2. Baseline nutritional indicators of the three supplementation groups.

\begin{tabular}{|c|c|c|c|}
\hline \multicolumn{3}{|c|}{ Intervention $\mathrm{n}=93$} & \multirow{2}{*}{$\begin{array}{c}\text { Control } \\
\mathbf{n}=68(\%)\end{array}$} \\
\hline & $\begin{array}{c}\text { RUTF } \\
\mathrm{n}=25(\%)\end{array}$ & $\begin{array}{c}\text { Pushti packet } \\
\mathrm{n}=68(\%)\end{array}$ & \\
\hline \multicolumn{4}{|l|}{ Gender } \\
\hline Male & $12(48)$ & $28(41.2)$ & $28(41.2)$ \\
\hline Female & $13(52)$ & $40(58.8)$ & $40(58.8)$ \\
\hline \multicolumn{4}{|c|}{ Initiation of breast feeding } \\
\hline Within 1 hour & $11(44)$ & $37(54.4)$ & $37(54.4)$ \\
\hline After 1 hour & $14(56)$ & $31(45.6)$ & $31(45.6)$ \\
\hline \multicolumn{4}{|c|}{ Colostrum feeding } \\
\hline Yes & $23(92)$ & 65 (95.6) & 63 (92.6) \\
\hline No & $2(8)$ & $3(4.4)$ & $5(7.4)$ \\
\hline \multicolumn{4}{|c|}{ History of pre-lacteal feeding } \\
\hline Yes & $12(48)$ & $21(30.9)$ & $18(26.5)$ \\
\hline No & $13(52)$ & $47(69.1)$ & $50(73.5)$ \\
\hline \multicolumn{4}{|c|}{ Exclusive breast feeding $^{\mathrm{a}}$} \\
\hline No EBF & $8(40)$ & $5(10.2)$ & $10(17.5)$ \\
\hline$<3$ months & $3(15)$ & $16(32.7)$ & $13(22.8)$ \\
\hline 3 - 5 months & $8(40)$ & $24(49)$ & 33 (57.9) \\
\hline 6 months & $1(5)$ & $4(8.2)$ & $1(1.8)$ \\
\hline \multicolumn{4}{|c|}{ Introduction of soft and semisolid food } \\
\hline$<6$ months & $19(76)$ & $47(69.1)$ & $48(70.6)$ \\
\hline 6 - 9 months & $5(20)$ & 21 (30.9) & 19 (27.9) \\
\hline$>9$ months & $1(4)$ & $0(0)$ & $1(1.5)$ \\
\hline \multicolumn{4}{|c|}{ Vitamin A in the last six month } \\
\hline Yes & $13(52)$ & $48(70.6)$ & $40(58.8)$ \\
\hline No & $12(48)$ & $20(29.4)$ & $28(41.2)$ \\
\hline \multicolumn{4}{|c|}{ Iodized salt for cooking } \\
\hline Yes & $24(96)$ & $68(100)$ & 67 (98.5) \\
\hline No & $1(4)$ & $0(0)$ & $1(1.5)$ \\
\hline
\end{tabular}

${ }^{a}$ Exclusive breast feeding: mothers were asked about at what age (in days) did they first give their child plain water, sugar water, or juice or cow or goat milk.

Table 3. Weight increment (gm) in different intervention groups at different point of time.

\begin{tabular}{|c|c|c|c|c|}
\hline & RUTF $n=25$ & Pushti packet (PP) n = 68 & Control $n=68$ & \\
\hline 1 month & $367(-40,890)$ & $180(-240,1440)$ & $120(-750,1280)$ & $\begin{array}{l}\text { RUTF vs PP: } p=0.038 \\
\text { RUTF vs Con: } p=0.029\end{array}$ \\
\hline 2 month & $727(-100,1080)$ & $390(-380,1540)$ & $280(-600,920)$ & $\begin{array}{c}\text { RUTF vs PP: } p=0.001 \\
\text { RUTF vs Con: } p=0.000 \\
\text { PP vs Con: } p=0.082\end{array}$ \\
\hline 3 month & $822(260,1670)$ & $530(-380,1940)$ & $430(-560,1380)$ & $\begin{array}{l}\text { RUTF vs PP: } p=0.009 \\
\text { RUTF vs Con: } p=0.002\end{array}$ \\
\hline 4 month & $1050(470,1670)$ & $640(-80,2400)$ & $635(-350,1550)$ & $\begin{array}{l}\text { RUTF vs PP: } p=0.001 \\
\text { RUTF vs Con: } p=0.001\end{array}$ \\
\hline 5 month & $1085(510,1520)$ & $790(170,2220)$ & $730(-680,1660)$ & $\begin{array}{l}\text { RUTF vs PP: } p=0.029 \\
\text { RUTF vs Con: } p=0.019\end{array}$ \\
\hline
\end{tabular}

Median (range).

not significant at any interval.

\section{Discussion}

This study compared the rate of weight gain and absolute weight gain achieved in malnourished children by 


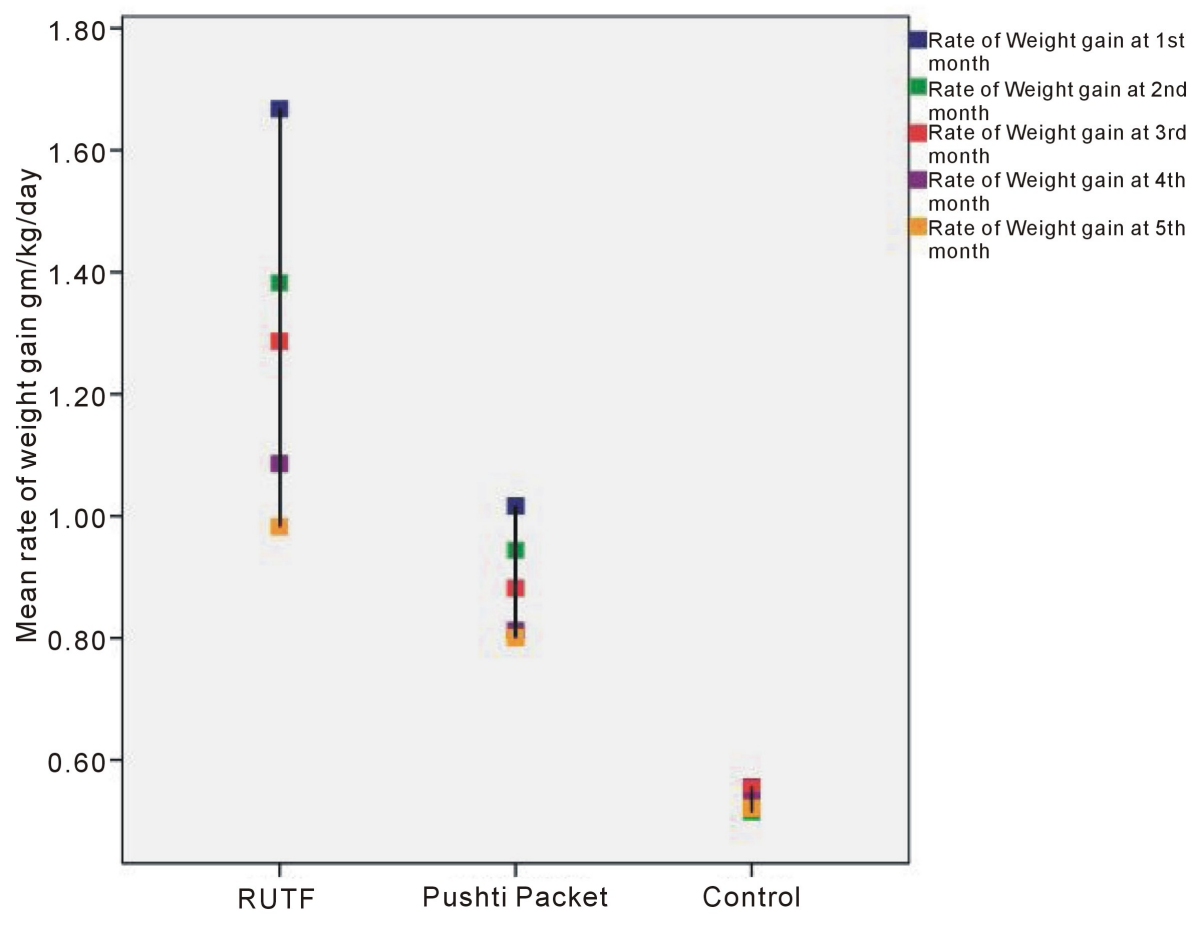

Figure 2. Rate of weight gain (gm/kg/day).

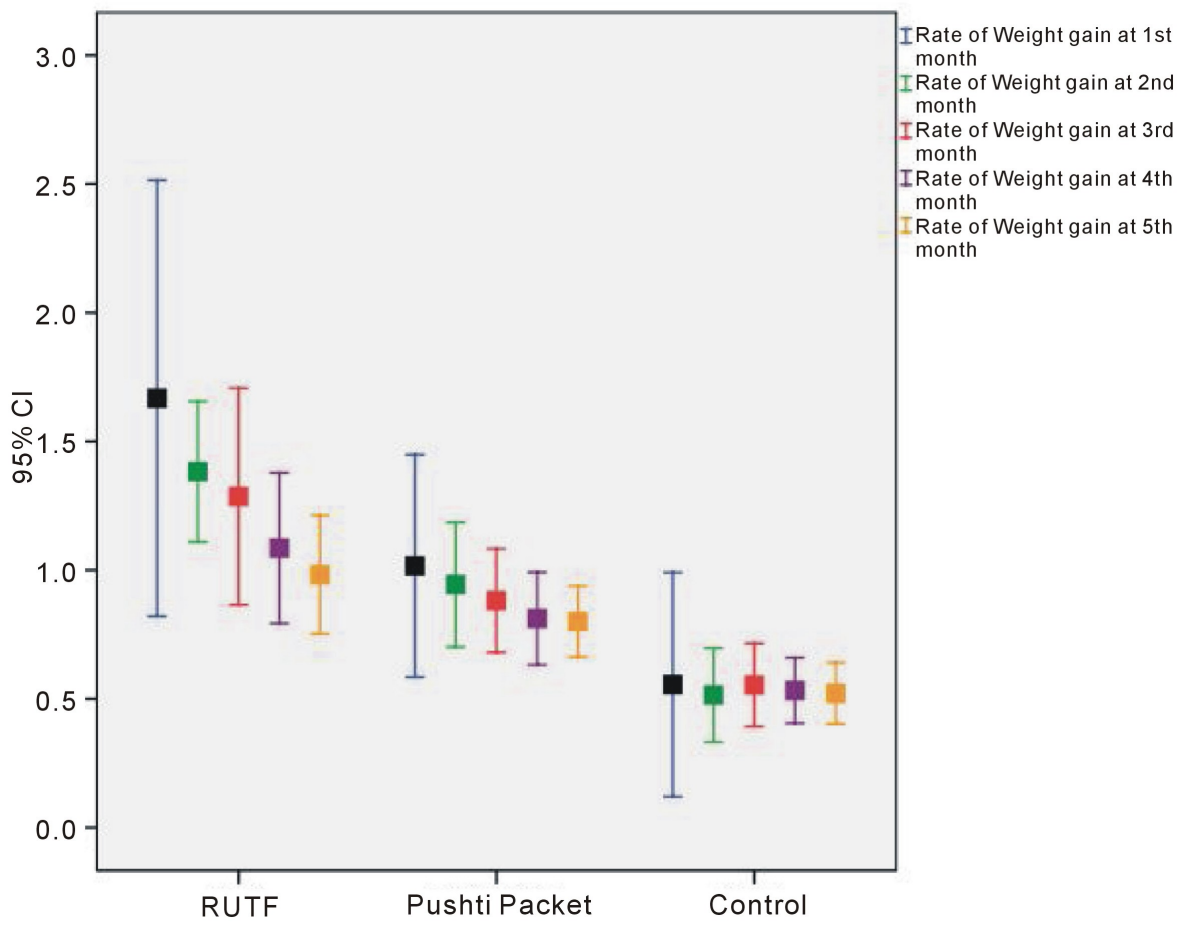

Figure 3. Mean rate of weight gain (gm/kg/day) with $95 \%$ CI.

consuming three different regimens of food supplementation over a period of 5 months.

There was no difference in terms of overall rate of weight gain or rate of weight gain at any month interval between the RUTF and the locally made Pushti packet groups. Additionally, rate of weight gain achieved by the malnourished children are significantly different and higher in comparison to the control group. However, abso- 
lute weight gain achieved by the RUTF group is significantly higher than the other two groups during the $2^{\text {nd }}, 3^{\text {rd }}$ and $4^{\text {th }}$ months.

In a study in Malawi, the mean weight gain was $12.5 \%$ of the baseline body weight for moderately malnourished children over a period of 28 days when treated with a regular RUTF [16]. The Sphere standards for therapeutic feeding program are a minimum of $8 \mathrm{~g} / \mathrm{kg} /$ day for children with severe acute malnutrition [17]. However, there is a lack of existing literature about the nutrition requirements or recommendation on rate of weight gain needed to be achieved for moderately malnourished children. Assuming that the nutritional requirement for moderately malnourished children is between the nutritional needs of a recovering severely malnourished child and a normal child, it has been postulated that the diet recommended for moderately malnourished children should enable a rate of weight gain of at least $5 \mathrm{~g} / \mathrm{kg} /$ day [18].

This study showed that the rate of weight gain achieved by using RUTF to be only $1.69 \mathrm{~g} / \mathrm{kg} /$ day for children suffering from moderate-to-severe malnutrition for the first month or $1.28 \mathrm{~g} / \mathrm{kg} / \mathrm{day}$ on average for the five month period. Our finding is in concordance with a study in India, where they found the rate of weight gain to be $1 \mathrm{~g} / \mathrm{kg} /$ day among moderately malnourished children with RUTF supplementation for a month [19].

\section{Limitations}

This study was not a randomized control trial, nor did it have a sufficient sample size. But the strength of the study lies in its robustness as a well-executed operational research at community level. Therefore, we need to explore further with a larger sample size and search for other possible confounders, maintaining the same integrity as with this operations research.

\section{Conclusion}

This study observed that in respect of community-based treatment of moderate to severe malnutrition, better weight gain was achieved with RUTF after 5 months of supplementation, but the rate of weight gain between RUTF and Pushti packet was comparable. Pushti packet prevented further deterioration of nutritional status among malnourished children. Considering sustainability and cost-effectiveness, the only solution could be to improve food security in general and to develop ready-to-use food from local ingredients that can be cost-effective and sustainable particularly for children of food insecure households.

\section{Acknowledgements}

This research protocol is funded by University of Virginia (UVA) (GR-00681) with support from MAL-ED Network Investigators in the Foundation of National Institute of Health (FNIH), Fogarty International Centre (FIC) with overall support from the Bill \& Melinda Gates Foundation. icddr, b acknowledges with gratitude the commitment of UVA, FNIH, FIC and BMGF to its research efforts. icddr, b also gratefully acknowledges the following donors which provide unrestricted support: Australian Agency for International Development (AusAID), Government of the People's Republic of Bangladesh, Canadian International Development Agency (CIDA), Swedish International Development Cooperation Agency (SIDA), and the Department for International Development, UK (DFID).

\section{References}

[1] Black, R.E., Allen, L.H., Bhutta, Z.A., Caulfield, L.E., De Onis, M., et al. (2008) Maternal and Child Undernutrition: Global and Regional Exposures and Health Consequences. Lancet, 371, 243-260. http://dx.doi.org/10.1016/S0140-6736(07)61690-0

[2] Ahmed, T., Haque, R., Shamsir Ahmed, A.M., Petri Jr., W.A. and Cravioto, A. (2009) Use of Metagenomics to Understand the Genetic Basis of Malnutrition. Nutrition Reviews, 67, S201-S206. http://dx.doi.org/10.1111/j.1753-4887.2009.00241.x

[3] UNICEF (2013) Understanding Malnutrition Global Nutrition Cluster. www.unicef.org/nutritioncluster/files/M03P1.doc

[4] WFP (2013) What Is Malnutrition? Hunger. http://www.wfp.org/hunger/malnutrition

[5] Black, R.E., Victora, C.G., Walker, S.P., Bhutta, Z.A., Christian, P., et al. (2013) Maternal and Child Undernutrition and Overweight in Low-Income and Middle-Income Countries. Lancet, 382, 427-451. 
http://dx.doi.org/10.1016/S0140-6736(13)60937-X

[6] Lobo, D.A., Velayudhan, R., Chatterjee, P., Kohli, H. and Hotez, P.J. (2011) The Neglected Tropical Diseases of India and South Asia: Review of Their Prevalence, Distribution, and Control or Elimination. PLoS Neglected Tropical Diseases, 5, Article ID: e1222. http://dx.doi.org/10.1371/journal.pntd.0001222

[7] Michaelsen, K.F., Hoppe, C., Roos, N., Kaestel, P., Stougaard, M., et al. (2009) Choice of Foods and Ingredients for Moderately Malnourished Children 6 Months to 5 Years of Age. Food \& Nutrition Bulletin, 30, S343.

[8] Protein Energy Malnutrition (PEM) (2009).

[9] Briend, A. and Prinzo, Z.W. (2009) Dietary Management of Moderate Malnutrition: Time for a Change. Food \& Nutrition Bulletin, 30, S265.

[10] De Pee, S. and Bloem, M.W. (2009) Current and Potential Role of Specially Formulated Foods and Food Supplements for Preventing Malnutrition among 6- to 23-Month-Old Children and for Treating Moderate Malnutrition among 6- to 59-Month-Old Children. Food \& Nutrition Bulletin, 30, S434-S463.

[11] Matilsky, D.K., Maleta, K., Castleman, T. and Manary, M.J. (2009) Supplementary Feeding with Fortified Spreads Results in Higher Recovery Rates than with a Corn/Soy Blend in Moderately Wasted Children. The Journal of Nutrition, 139, 773-778. http://dx.doi.org/10.3945/jn.108.104018

[12] Nackers, F., Broillet, F., Oumarou, D., Djibo, A., Gaboulaud, V., et al. (2010) Effectiveness of Ready-To-Use Therapeutic Food Compared to a Corn/Soy-Blend-Based Pre-Mix for the Treatment of Childhood Moderate Acute Malnutrition in Niger. Journal of Tropical Pediatrics, 56, 407-413. http://dx.doi.org/10.1093/tropej/fmq019

[13] World Health Organization, World Food Programme, United Nations System Standing Committee on Nutrition, United Nations Children's Fund (2007) Community-Based Management of Severe Acute Malnutrition. World Health Organization, Geneva, 1-8.

[14] MAL-ED (2013) The Interactions of Malnutrition \& Enteric Infections: Consequences for Child Health and Development. http://mal-ed.fnih.org/

[15] Nutriset (2013) Plumpy’Nut ${ }^{\circledR}$ Ready-to-Use Therapeutic Food (RUTF). http://www.nutriset.fr/en/product-range/produit-par-produit/plumpy-nut-ready-to-use-therapeutic-food-rutf.html

[16] Ciliberto, M.A., et al. (2005) Comparison of Home-Based Therapy with Ready-to-Use Therapeutic Food with Standard Therapy in the Treatment of Malnourished Malawian Children: A Controlled, Clinical Effectiveness Trial. The American Journal of Clinical Nutrition, 81, 864-870.

[17] Sphere Project (2004) Humanitarian Charter and Minimum Standards in Disaster Response.

[18] Golden, M.H. (2009) Proposed Recommended Nutrient Densities for Moderately Malnourished Children. Food \& Nutrition Bulletin, 30, S267.

[19] Singh, A.S., Kang, G., Ramachandran, A., Sarkar, R., Peter, P., et al. (2010) Locally Made Ready-to-Use Therapeutic Food for Treatment of Malnutrition: A Randomized Controlled Trial. Indian Pediatrics, 47, 679-686.

http://dx.doi.org/10.1007/s13312-010-0100-8 
Scientific Research Publishing (SCIRP) is one of the largest Open Access journal publishers. It is currently publishing more than 200 open access, online, peer-reviewed journals covering a wide range of academic disciplines. SCIRP serves the worldwide academic communities and contributes to the progress and application of science with its publication.

Other selected journals from SCIRP are listed as below. Submit your manuscript to us via either submit@scirp.org or Online Submission Portal.
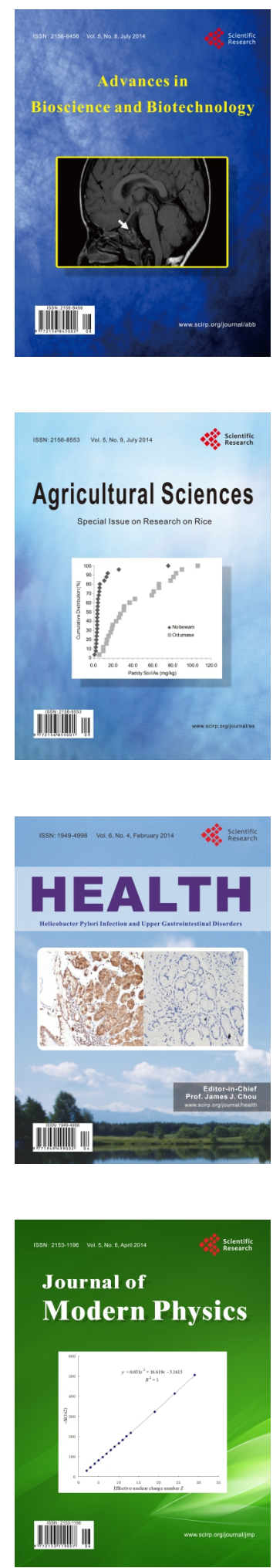
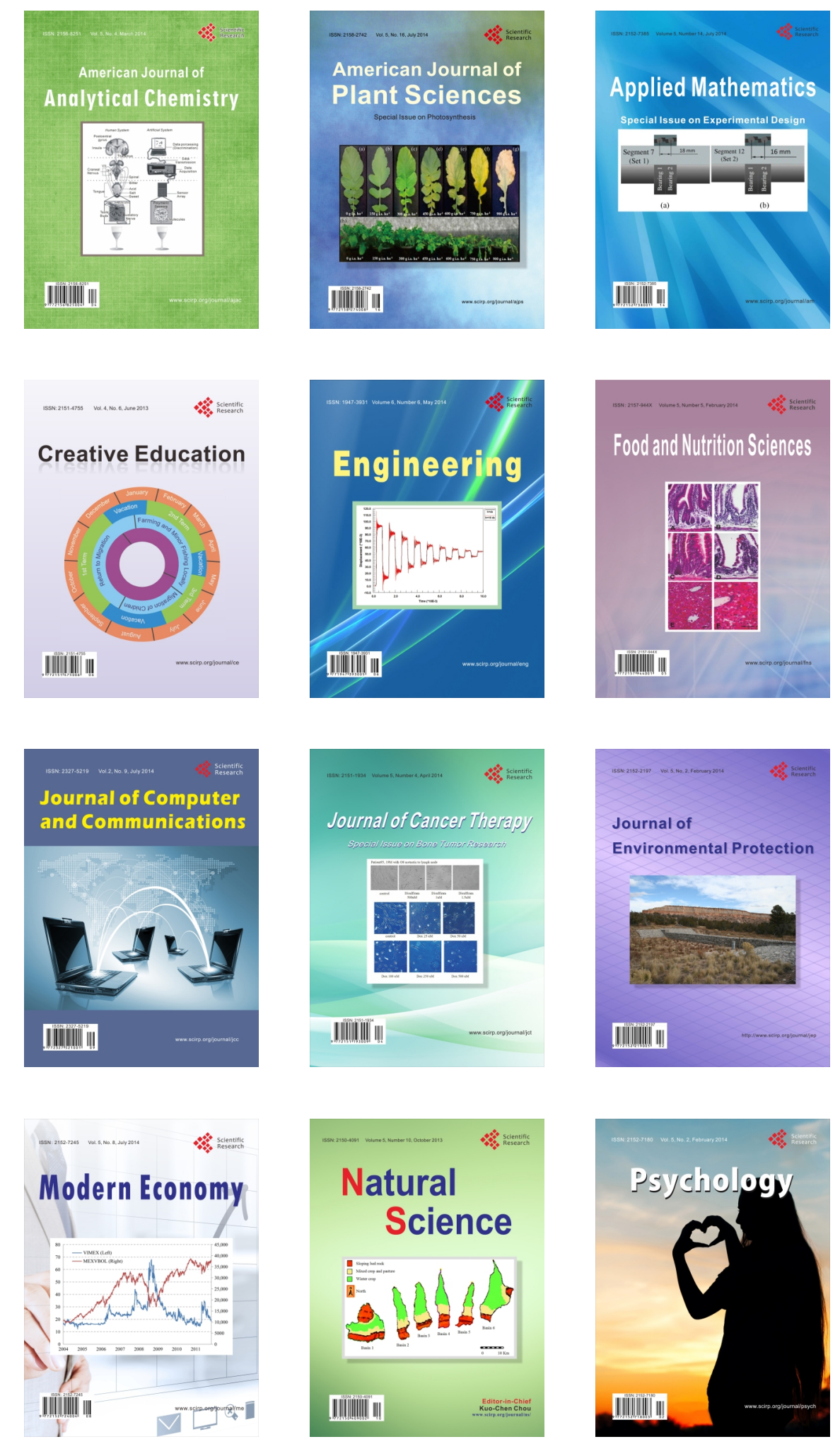